\title{
Longitudinal survey of ischaemic heart disease in randomly selected sample of older population
}

\author{
A. H. KITCHIN AND J. S. MILNE \\ From the Department of Medicine, Western General Hospital, and the \\ Royal Victoria Hospital, Edinburgh
}

A group of 215 men and 272 women aged 62 to 90 forming a randomly-selected sample of the older population was studied by cardiovascular survey methods and followed for 5 years. The 5-year mortality of 28 per cent was related to age and was higher in men. Ischaemic heart disease was the certified cause of 28 per cent of the deaths. Mortality was greater in those with systolic hypertension. Among electrocardiographic features $S T$ depression, $T$ inversion, and atrial fibrillation increased overall and ischaemic heart disease mortality independently of their association with age. A positive response to an angina and infarct questionnaire was poorly related to subsequent mortality.

Re-examination of 72 per cent of 5-year survivors was possible. Systolic and diastolic blood pressures were significantly lower and the frequency of electrocardiographic abnormalities, particularly left axis deviation, left ventricular hypertrophy, and ST and $T$ wave changes, was increased.

In an earlier paper we reported (Kitchin et al., 1973) on the prevalence of various manifestations of ischaemic heart disease in 487 subjects aged 62 to 90 who formed a randomly selected sample of the 27000 older people living in a defined area of Edinburgh. Briefly this showed that 10 per cent gave a history of angina; 44 per cent had no codable electrocardiographic abnormality, 6 per cent had electrocardiographic abnormalities strongly suggestive of ischaemic heart disease, and a further 24 per cent had changes possibly caused by ischaemic heart disease. Pronounced left axis deviation was found in $\mathbf{8 . 8}$ per cent. Electrocardiographic evidence of ischaemic heart disease increased with age. Smoking habits, obesity, and hypertension were unrelated to manifestations of ischaemic heart disease.

This group of subjects was followed for 5 years from the initial survey and the survivors were restudied by the same methods and by the same observers. The object was to record mortality rates and the incidence of new manifestations of ischaemic heart disease in the 5-year period, and to relate these to subject characteristics at the start of the study.

\section{Subjects and methods}

The subjects were 215 men and 272 women aged Received 15 October 1976
62 to 90 years. The method of sampling, including a comparison of respondents and non-respondents, has been described elsewhere (Milne et al., 1971).

Standardised validated techniques were used (Kitchin et al., 1973) and measures of reproducibility were obtained. The cardiovascular survey, which formed part of a larger survey, comprised the following:

(1) Rose's questionnaire in respect of angina pectoris and possible myocardial infarction (Rose and Blackburn, 1968).

(2) Twelve-lead electrocardiogram coded independently by two observers using the Minnesota code (Blackburn et al., 1960). The same instrument was used throughout the study.

(3) Six-foot posteroanterior radiograph of the chest.

(4) Height, weight, skinfold thickness, and blood pressure using the London School of Hygiene instrument.

(5) Questionnaire on respiratory disease and smoking (Medical Research Council, 1965).

(6) General medical examination recorded on prepared proformata.

The $\chi^{2}$ test was used to estimate the statistical significance of observed differences in the results.

\section{Results}

(1) MORTALITY AND CAUSE OF DEATH Of the original 487 subjects, 138 died during the 
5 -year period, an overall mortality of 28.3 per cent. Of these, 37 were certified as dying from myocardial infarction or ischaemic heart disease and 2 others from myocardial failure; the remaining 99 were non-cardiac deaths except for 2 from valvular heart disease. The expected death rate from national mortality statistics was 29.0 per cent (males $36 \%$, females $24 \%$ ). Table 1 shows mortality related to age and sex separating ischaemic heart disease from other deaths. In calculating death rate from ischaemic heart disease allowance has been made for the fact that those dying from non-cardiac causes were at risk of ischaemic heart disease death for $2 \frac{1}{2}$ years on average.

Mortality was higher in men and increased with age in both sexes. A possible relation to the following factors noted at the first examination was sought: positive response to Rose's questionnaire in respect of angina or infarction, systolic or diastolic hypertension, and specific electrocardiographic abnormalities.

Five-year mortality in those with a history of angina was $10 / 53(19 \%)$ and in those without such a history it was $122 / 427(29 \%)$. Deaths in those giving a history of infarction were $8 / 32(25 \%)$ as compared with $125 / 449(28 \%)$ in those without this history.

Table 2 shows the increased mortality in subjects with systolic or diastolic hypertension. In the case of the former, ischaemic heart disease accounts for a large proportion of the increased mortality. If we take levels of 160 and 100 as upper normal values, mortality from ischaemic heart disease was higher both for men and women with pressures over these levels.

Table 3 shows the 5 -year overall and ischaemic heart disease mortality first in subjects with no codable electrocardiographic abnormality and then

Table 1 5-year mortality in 487 subjects

\begin{tabular}{|c|c|c|c|c|}
\hline & No. & $\begin{array}{l}\text { Per cent } \\
\text { mortality }\end{array}$ & $\begin{array}{l}\text { Deaths from } \\
\text { ischaemic heart } \\
\text { disease as per cent } \\
\text { of all deaths }\end{array}$ & $\begin{array}{l}\text { Estimated death rate } \\
\text { from ischaemia heart } \\
\text { disease }(\%)\end{array}$ \\
\hline All subjects & 487 & 28 & 28 & 8.9 \\
\hline $\begin{array}{l}\text { Men } \\
60-69 \\
70+ \\
\text { All }\end{array}$ & $\begin{array}{r}122 \\
93 \\
215\end{array}$ & $\begin{array}{l}28 \\
47 \\
36\end{array}$ & $\begin{array}{l}35 \\
27 \\
31\end{array}$ & $\begin{array}{l}10 \cdot 8 \\
15 \cdot 6 \\
12 \cdot 7\end{array}$ \\
\hline $\begin{array}{l}\text { Women } \\
60-69 \\
70+ \\
\text { All }\end{array}$ & $\begin{array}{l}137 \\
135 \\
272\end{array}$ & $\begin{array}{l}12 \\
33 \\
22\end{array}$ & $\begin{array}{r}6 \\
32 \\
25\end{array}$ & $\begin{array}{r}0.8 \\
11 \cdot 7 \\
6.4\end{array}$ \\
\hline $\begin{array}{l}\text { All } 60-69 \\
\text { All } 70+\end{array}$ & $\begin{array}{l}259 \\
228\end{array}$ & $\begin{array}{l}19 \\
40\end{array}$ & $\begin{array}{l}26 \\
30\end{array}$ & $\begin{array}{r}5 \cdot 4 \\
13 \cdot 2\end{array}$ \\
\hline
\end{tabular}

Table 2 5-year mortality and blood pressure

\begin{tabular}{lrlll}
\hline $\begin{array}{l}\text { Blood } \\
\text { Pressure } \\
\text { (mmHg) }\end{array}$ & No. $\begin{array}{l}\text { Per cent } \\
\text { mortality }\end{array}$ & $\begin{array}{l}\text { Deaths from } \\
\text { ischaemic heart } \\
\text { disease as per cent } \\
\text { of all deaths }\end{array}$ & $\begin{array}{l}\text { Estimated ischaemic } \\
\text { heart disease death } \\
\text { rate (\%) }\end{array}$ \\
\hline $\begin{array}{l}\text { Systolic } \\
\geqslant 160\end{array}$ & 226 & 31 & 38 & $12 \cdot 7^{\star}$ \\
$\leqslant 160$ & 261 & 23 & 19 & $5 \cdot 6^{\star}$ \\
$\begin{array}{c}\text { Diastolic } \\
\geqslant 100\end{array}$ & 76 & 38 & 31 & $13 \cdot 8$ \\
$\leqslant 100$ & 411 & 27 & 28 & $8 \cdot 1$ \\
\hline
\end{tabular}

$\star \mathrm{P}<0.005$.

in groups with specific abnormalities. All types of electrocardiographic abnormality greatly increased the death rate from ischaemic heart disease, which was low $(3.8 \%$ ) and accounted for only 14 per cent of deaths in those with normal electrocardiograms at the start of the study. Atrial fibrillation was particularly unfavourable though numbers are small and comparison difficult. Left anterior hemiblock pattern, present in 8.8 per cent of subjects, did not significantly affect 5-year mortality.

Since both the prevalence of electrocardiographic abnormalities and mortality increase with age, the expected mortality in the absence of the specific electrocardiographic code was calculated for separate age groups, and the resulting total expected mortality compared with the observed number of deaths in those having the electrocardiographic abnormality. This shows that ST depression, $T$ inversion, and atrial fibrillation have an unfavourable effect independent of their association with age.

Reid et al. (1966) made a further classification based on the Minnesota code with the object of selecting electrocardiograms indicating probable ischaemic heart disease $\left(I_{1-2}\right.$ or $\left.V_{1 I}\right)$ and possible ischaemic heart disease $\left(I_{3}\right.$ or $\mathrm{IV}_{1^{-3}}$ or $\left.\mathrm{V}_{1^{-3}}\right)$. These two groups showed the highest estimated death rates from ischaemic heart disease $(13.2 \%)$ and overall death rates $(43 \%)$ and this applied to women as much as to men and to the lower as well as to the higher age group.

CHANGES IN 5-YEAR SURVIVORS (252 subjects) Of the 349 subjects who survived 5 years, it was possible to re-examine $252(72 \%)$. In these subjects a comparison was possible as regards response to angina questionnaire, blood pressure, and electrocardiographic coding (Tables 4,5 ).

There was little overall change in frequency of positive questionnaire responses, but this conceals a considerable amount of individual change, e.g. nearly half the patients who gave a history of angina 
Table 3 5-year mortality and electrocardiogram Minnesota coding

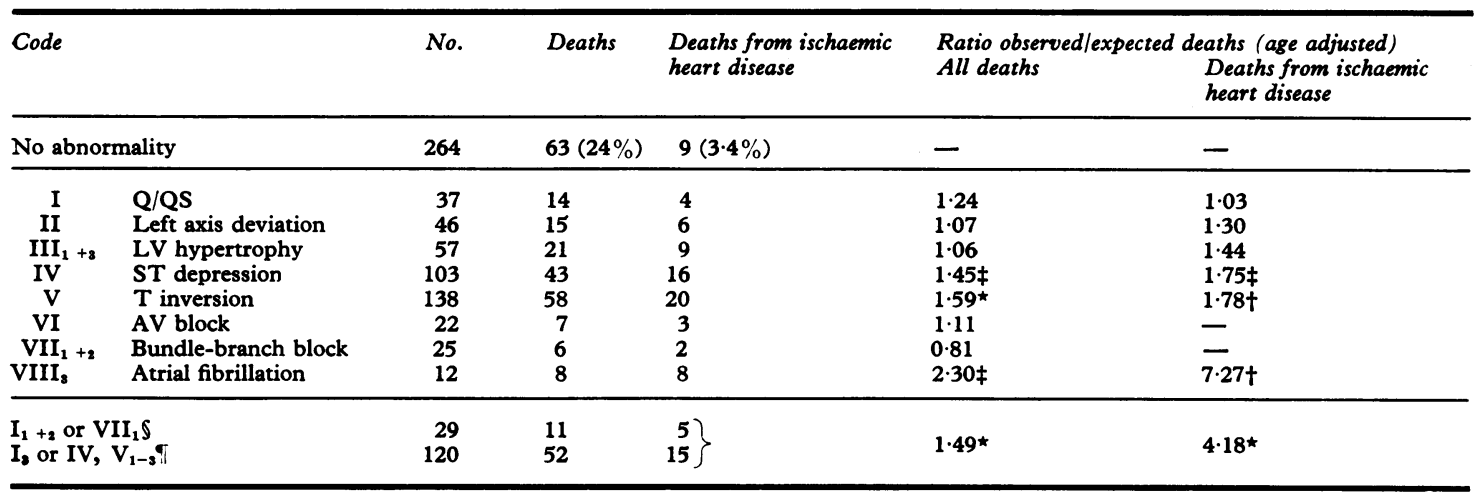

$\star P<0.005 ;+P<0.010 ; \ddagger P<0.02$.

$\$ \mathrm{I}_{1+2}$ or $V I I_{1}$, probable ischaemic heart disease; $\left\{\mathrm{I}_{3}\right.$ or $\mathrm{IV}, \mathrm{V}_{1,3}$, possible ischaemic heart disease. Classification of Reid et al. (1966). 'Probable' ischaemic heart disease represents major $Q$ and $Q S$ patterns or left bundle-branch block, 'possible' minor $Q$ abnormalities or ST-T changes.

at the first survey did not do so at the second, while none of those who gave a positive response for infarction at the first interview did so at the second.

Blood pressure fell from $151 \cdot 6 \pm 2 \cdot 4 \mathrm{mmHg}$ systolic and $79 \pm 1.3 \mathrm{mmHg}$ diastolic to $145 \cdot 6 \pm 2 \cdot 5$ and $77.8 \pm 1.3$ respectively in men, and from $163 \cdot 3 \pm 2 \cdot 2$ systolic and $88 \cdot 3 \pm 1 \cdot 3$ diastolic to $148 \cdot 3 \pm 2 \cdot 1$ and $82 \cdot 6 \pm 1 \cdot 3$ in women. The magnitude of the fall was related statistically to the height of the initial pressure.

There was an increased frequency of all electrocardiographic abnormalities at the second survey, particularly for left axis deviation, left ventricular hypertrophy, ST-T changes, bundle-branch block, and atrial fibrillation. Where criteria depend on precise voltage measurement (ventricular hypertrophy and ST-T changes) it is perhaps not surprising that some which are outside the normal range on the first examination are within it at the second, despite careful attention to standardisation.

\section{Discussion}

The observed 5-year death rate in this randomly selected sample of the older population coincides closely with that predicted from national mortality

Table 4 Change in 5-year survivors (252 subjects) response to angina and infarct questionnaire

\begin{tabular}{llll}
\hline & $\begin{array}{l}\text { Initial positive } \\
\text { response }\end{array}$ & $\begin{array}{l}\text { Change after } \\
5 \text { years }\end{array}$ & $\begin{array}{l}\text { Final positive } \\
\text { response }\end{array}$ \\
\hline Angina & $31 / 252(12 \%)$ & $-14+16$ & $33 / 252(13 \%)$ \\
Infarct & $14 / 252(6 \%)$ & $-14+6$ & $\begin{array}{c}6 / 252(2 \%) \\
\text { Neither }\end{array}$ \\
$215 / 252(86 \%)$ & $-18+19$ & $216 / 252(86 \%)$ \\
\hline
\end{tabular}

statistics (Registrar General for Scotland, 1974). This gives confidence in the unselected nature of the sample.

The causes of death were found from certification data and the calculated death rates from ischaemic heart disease must, therefore, be regarded as tentative only. With this caveat, ischaemic heart disease accounted for 28 per cent of the 138 deaths in the 5 -year period ( $31 \%$ in men and $25 \%$ in women), a figure that is rather less than expected from national statistics (37 and $36 \%$ respectively). The data confirm the sharp rising death rate with age and the higher rates in men than those in women.

An object of the longitudinal study was to examine the predictive value of patient characteristics related to ischaemic heart disease at the start of the study in respect of subsequent mortality. Positive responses to the angina and infarction questionnaire of Rose and Blackburn (1968) were unrelated to mortality in this series of subjects, though it should be noted that numbers at risk were relatively small (53 and 32). It might have been expected that those with a positive response would fare worse. However, the variability of response shown when the subjects were tested a second time must cast doubt on the reliability of the answers in older subjects, in addition to the well-known difficulty in relating chest pain to cardiac pathology in the individual case. Repeatability of the angina questionnaire has been found to be poor in both middle-aged (Rose, 1968; Zeiner-Henriksen, 1972) and elderly (Milne et al., 1969) subjects.

Systolic hypertension significantly increased mortality from ischaemic heart disease. Diastolic hypertension appeared to do so also (Fig. 1), though perhaps because of the small numbers statistical 
Table 5 Changes in electrocardiographic Minnesota coding in 5-year survivors (252 subjects)

\begin{tabular}{|c|c|c|c|c|c|}
\hline & & $\begin{array}{l}\text { Initial positive } \\
\text { finding }\end{array}$ & $\begin{array}{l}\text { Change after } \\
5 \text { years }\end{array}$ & $\begin{array}{l}\text { Final positive } \\
\text { finding }\end{array}$ & $\begin{array}{l}5 \text {-year increase in } \\
\text { frequency }(\%)\end{array}$ \\
\hline $\begin{array}{l}\text { I } \\
\text { III }_{1+8} \\
\text { IV } \\
\text { V } \\
\text { VI } \\
\text { VII }_{1+2} \\
\text { VIII }_{2}\end{array}$ & $\begin{array}{l}\text { Q/QS } \\
\text { Left axis deviation } \\
\text { Left ventricular hypertrophy } \\
\text { ST depression } \\
\text { T inversion } \\
\text { Atrioventricular block } \\
\text { Bundle branch block } \\
\text { Atrial fibrillation }\end{array}$ & $\begin{array}{l}16 / 252(6 \%) \\
21 / 252(8 \%) \\
31 / 252(12 \%) \\
39 / 252(15 \%) \\
52 / 252(21 \%) \\
11 / 252(4 \%) \\
16 / 252(6 \%) \\
12 / 252(5 \%)\end{array}$ & $\begin{aligned}-6 & +9 \\
-3 & +22 \\
-9 & +25 \\
-11 & +28 \\
-13 & +31 \\
-6 & +7 \\
-3 & +10 \\
-6 & +17\end{aligned}$ & $\begin{array}{l}19 / 252(8 \%) \\
40 / 252(16 \%) \\
47 / 252(19 \%) \\
56 / 252(22 \%) \\
70 / 252(28 \%) \\
12 / 252(5 \%) \\
23 / 252(9 \%) \\
23 / 252(9 \%)\end{array}$ & $\begin{array}{l}2 \\
8 \\
7 \\
7 \\
7 \\
1 \\
3 \\
4\end{array}$ \\
\hline
\end{tabular}

significance was not reached. The effect of systolic hypertension on overall mortality was significant only in women. During a 14-year period in the Framingham study a raised systolic blood pressure was more strongly associated with development of ischaemic heart disease than was raised diastolic pressure (Kannel et al., 1971), and the importance of systolic pressure in this association was greater with increasing age.

Ischaemic changes in the initial cardiogram, defined by Rose and Blackburn, had a strong predictive value, increasing the ischaemic heart disease death rate fourfold and the overall death rate by 50 per cent. ST and T wave abnormalities and atrial fibrillation indicated a particularly poor prognosis. Higgins et al. (1963), studying a younger sample of the male population aged 35 to 64 , also noted an increased risk of dying, and of being recorded as dying

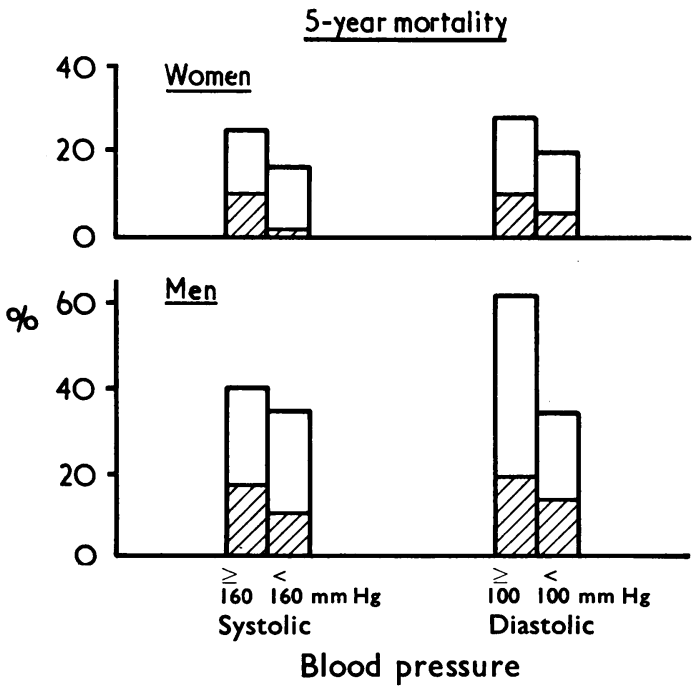

Fig. 1 Five-year mortality (\%) related to initial level of systolic and diastolic blood pressure in men and women. Cross-hatching represents deaths from ischaemic heart disease. a cardiac death, where the electrocardiogram was compatible with ischaemic heart disease, showing Minnesota Code items I, IV, and V.

We can, from the present data, record the new occurrence of electrocardiographic abnormalities in the 5-year period in the 252 examined survivors. Numerically the greatest increase is in $\mathbf{T}$ wave inversion (7\%) and ST depression (7\%) followed by left ventricular voltage increases $(7 \%)$ and left axis deviation ( $8 \%$ ). Proportionately high increases, however, also occur in atrial fibrillation (5 to $9 \%$ ) and bundle-branch block ( 6 to $9 \%$ ). These changes reflect predominantly ischaemic or conduction system disease.

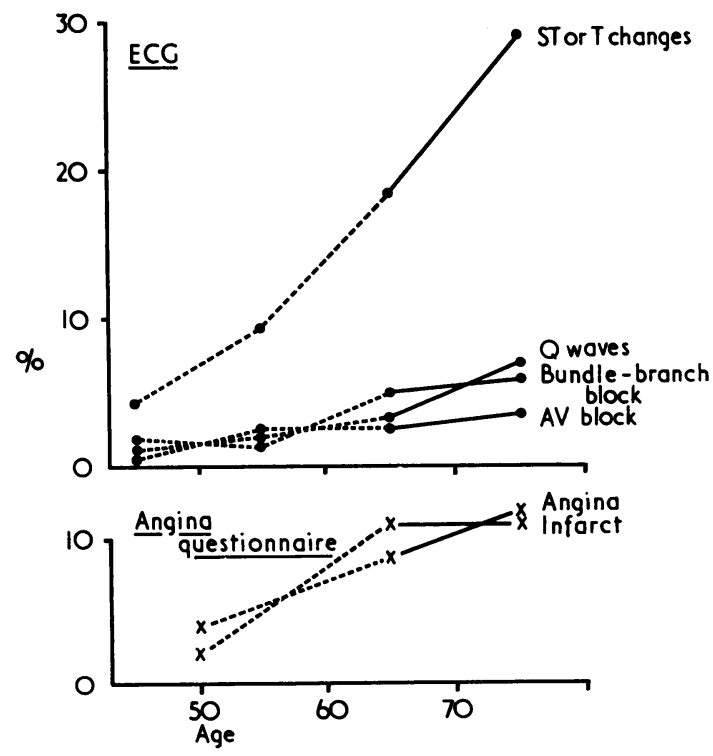

Fig. 2 Per cent prevalence of electrocardiographic features and questionnaire responses in groups of male subjects of different ages. Solid lines-present data. Dotted lines-data of Reid et al. (1966). 
It is interesting to compare the increased incidence recorded in the 5-year longitudinal study with the prevalence rates in different age groups at the start of the study (Fig. 2; Kitchin et al., 1973). The rates of increase with age of the prevalence of $T$ and ST changes, $Q$ waves, bundlebranch block, and atrioventricular block correspond closely with the observed incidence figures.

\section{Conclusion}

(1) The 5-year death rate in the older population is age- and sex-related. Both the overall death rate and deaths from ischaemic heart disease are strongly related to specific electrocardiographic abnormalities at the start of the period, ST depression, $T$ inversion, and atrial fibrillation, but unrelated to the angina questionnaire response. Mortality from ischaemic heart disease is related to systolic blood pressure.

(2) Questionnaire responses elicited at a 5-year interval were inconsistent in many cases.

(3) In this sample, representative of the older population, the cardiographic features of ST and $T$ wave changes, left ventricular hypertrophy, and left axis deviation each rose at a rate of approximately 1.5 per cent per annum. Conduction disturbances, atrial fibrillation, and $\mathrm{Q}$ wave changes developed much less frequently.

This study was supported by a grant from the Secretary of State for Scotland.

\section{References}

Blackburn, H., Keys, A., Simonson, E., Rautaharju, P., and Punsar, S. (1960). The electrocardiogram in population studies. A classification system. Circulation, 21, 1160-1175.

Higgins, I. T. T., Cochrane, A. L., and Thomas, A. J. (1963). Epidemiological studies of coronary disease. British fournal of Preventive and Social Medicine, 17, 153-165.

Kannel, W. B., Gordon, T., and Schwartz, M. J. (1971). Systolic versu is diastolic blood pressure and risk of coronary heart disease: the Framingham study. American fournal of Cardiology, 27, 335-346.

Kitchin, A. H., Lowther, C. P., and Milne, J. S. (1973). Prevalence of clinical and electrocardiographic evidence of ischaemic heart disease in the older population. British Heart fournal, 35, 946-953.

Medical Research Council Committee on the aetiology of chronic bronchitis (1965). Definition and classification of chronic bronchitis. Lancet, 1, 775-779.

Milne, J. S., Hope, K., and Williamson, J. (1969). Variability in replies to a questionnaire on symptoms of physical illness. Fournal of Chronic Diseases, 22, 805-810.

Milne, J. S., Maule, M. M., and Williamson, J. (1971). Method of sampling in a study of older people with a comparison of respondents and non-respondents. British fournal of Preventive and Social Medicine, 25, 37-41.

Registrar General for Scotland (1974). Annual Report 1973. H.M.S.O., Edinburgh.

Reid, D. D., Holland, W. W., Humerfelt, S., and Rose, G. A. (1966). A cardiovascular survey of British postal workers. Lancet, 1, 614-618.

Rose, G. A. (1968). Variability of angina. British fournal of Preventive and Social Medicine, 22, 12-15.

Rose, G. A., and Blackburn, H. (1968). Cardiovascular Survey Methods. World Health Organization, Geneva.

Zeiner-Henriksen, T. (1972). The repeatability at interview of symptoms of angina and possible infarction. fournal of Chronic Diseases, 25, 407-414.

Requests for reprints to Dr. A. H. Kitchin, Department of Medicine, Western General Hospital, Crewe Road, Edinburgh EH4 2XU. 